tres meses tras la fecha de recepción de la notificación por el Secretario General.

\section{Artículo 16 - Denuncia}

I. Toda Parte puede, en todo momento, denunciar la presente Convención dirigiendo una notificación al Secretario General del Consejo de Europa.

2. La denuncia tendrá efecto el primer día del mes que sigue a la expiración de un plazo de tres meses después de la fecha de recepción de la notificación por el Secretario General.

\section{Artículo 17 - Enmiendas}

I. Cualquier Parte o los Comités de expertos establecidos en el artículo 10 pueden proponer enmiendas a la presente Convención.

2. Toda propuesta de enmienda será notificada al Secretario General del Consejo de Europa que la comunicará a los Estados miembros del Consejo de Europa, a las otras Partes y a cada Estado europeo no miembro que haya sido invitado a adherirse a la presente Convención conforme a las disposiciones del artículo |4.

3. Cada propuesta de enmienda será examinada por los Comités de expertos establecidos en el artículo 10, que someterán el texto adoptado a la mayoría de tres cuartos de los representantes de las Par- tes en el Comité de Ministros para su adopción. Tras su adopción por el Comité de Ministros según la mayoría prevista en el artículo 20.d del Estatuto del Consejo de Europa y por unanimidad de los representantes de los Estados Parte que tengan el derecho de pertenecer al Comité de Ministros, el texto será transmitido a las Partes para su aceptación.

4. Cada enmienda entrará en vigor respecto a las Partes que la hayan aceptado el primer día del mes que sigue al plazo de tres meses tras la fecha en la que al menos tres Partes miembros del Consejo de Europa hayan informado al Secretario General de su aceptación. Para cualquier otra Parte que la acepte ulteriormente la enmienda entrará en vigor el primer día del mes que sigue al plazo de tres meses tras la fecha en la que dicha Parte haya informado al Secretario General de su aceptación.

\section{Artículo 18 - Notificaciones}

El Secretario General del Consejo de Europa notificará a los Estados miembros del Consejo de Europa, a todo Estado que se haya adherido a la presente Convención y, en su caso, a la Comunidad Europea:

a. toda signatura;

b. el depósito de todo instrumento de ratificación, de aceptación, de aprobación o de adhesión;

c. toda fecha de entrada en vigor de la pre- sente Convención, en conformidad con los artículos 13, 14 y 15;

d. toda declaración hecha en virtud del artículo I5;

e. toda denuncia hecha en virtud del artículo 16;

f. toda propuesta de enmienda, así como cualquier enmienda adoptada en conformidad con el artículo 17 y la fecha en la que dicha enmienda entra en vigor;

g. cualquier otro acto, notificación, información o comunicación relativa a la presente Convención.

Y para que conste, los que suscriben, debidamente autorizados al efecto, han firmado la presente Convención.

Hecha en Florencia el 20 de octubre de 2000, en francés y en inglés, los dos textos dan igualmente fe, en un sólo ejemplar que será depositado en los archivos del Consejo de Europa. El Secretario General del Consejo de Europa lo comunicará mediante copia certificada conforme a cada uno de los Estados miembros del Consejo de Europa, así como a cualquier otro Estado, o a la Comunidad Europea, invitados a adherirse a la presente Convención.

Traducción del texto oficial del Consejo de
Europa en francés, realizada por Florencio
Zoido Naranjo, miembro del Grupo de Ex-
pertos redactor del Informe Explicativo y
de la versión no jurídica de la presente
Convención.

Traducción del texto oficial del Consejo de Europa en francés, realizada por Florencio Zoido Naranjo, miembro del Grupo de Exde la versión no jurídica de la presente Convención.

\title{
Interacció 2000, el Encuentro de la gran Familia Cultural
}

1984, 1994, 1996, 1998 y 2000. Dieciséis años desde el primer encuentro, cinco convocatorias que han logrado una regularidad poco frecuente en el campo formativo, un alcance real sobre todo el territorio español, una dimensión internacional incontestable y un conjunto creciente de propuestas simultaneas.

Interacció 2000 ha demostrado haberse consolidado como un espacio de encuentro, reflexión, debate, formación y elaboración tan necesario en el sector cultural.

Durante tres días y medio algo más de 600 personas han compartido sus anhelos en un espacio que la Diputación de Barcelona ha sa- bido crear en la Casa de la Caridad de esta ciudad: el Centro de Estudios y Recursos Culturales y el Centro de Cultura Contemporánea de Barcelona que fueron diseñados como espacios para el debate y la reflexión cultural.

Este año se ha querido centrar el eje del encuentro en "Cultura y servicio público" en un momento que este último concepto va ensanchando su acepción implicando en él, y por lo tanto co-responsabilizando, no sólo a la administración de los servicios públicos, sino también al sector de colectivos y entidades de carácter asociativo así como a las empresas de servicios y a la industria cultural que más allá de las comprensibles lógicas del mercado, ven en la cultura un campo de acción que se extiende también en este terreno de lo público.

El núcleo de Interacció 2000 han sido 8 seminarios de 12 horas cada uno a lo largo de tres días. Todos ellos han abordado y desarrollado desde distintos sectores esta concepción de servicio público:

\footnotetext{
- "Municipio y redes artísticas: la promoción pública del espectáculo en vivo" Se ha centrado en la reflexión de las artes escénicas a escala local, en el papel que debe desarrollar la administración pública pero también los otros agentes implantados en el
} 
territorio. Se ha preocupado por dar respuestas a la necesidad de ampliar hacia nuevos públicos la asistencia a los espectáculos y cómo el trabajo en red ayuda a todo ello.

\section{- "La gestión del patrimonio: nuevos usos,} nuevos discursos"

Ha hecho un recorrido por 6 experiencias europeas que han profundizado en tres campos de acción en los que los museos deben renovar sus discursos: la gestión, los lenguajes expositivos y la revitalización del territorio. Las propuestas están ahí, ahora es función de cada uno reflexionar sobre su propio proyecto.

\section{- "Veinticinco años de casas de cultura"}

De la mano de la Asociación de Profesionales de la Gestión Cultural de Cataluña el seminario ha presentado el trabajo realizado en el Laboratorio operativo de reflexión sobre los centros culturales públicos impulsado por la Diputación de Barcelona durante todo el curso pasado. Asimismo se ha presentado la historia y el estado actual de los centros culturales en cinco realidades nacionales diferentes.

\section{- "Industrias culturales y políticas locales"}

Este seminario presentaba un tema poco abordado a nivel local: cómo los efectos de la industria cultural pueden y deben estimularse desde este nivel sin dejarlo sólo en manos de la administración del Estado central. Se ha abordado a partir de diferentes casos de pequeñas industrias culturales que han causado su impacto en diferentes ciudades.

- "Nuevos espacios para la cultura en Europa" Fruto de todo un trabajo anterior, el seminario se plantea como la presentación en público de sus observaciones, centradas en la necesidad de identificar nuevos equipamientos como centros culturales con especificidades propias. La mayoría de casos analizados han sido expuestos en el seminario.

\section{- "Los observatorios culturales en las regio- nes metropolitanas"}

¿Observatorios culturales a escala local? Esta es la tesis de que parte el seminario, mostrando algunos ejemplos y abordando la necesidad de un trabajo de análisis y observación de las políticas culturales a escala local en nuestro país.

\section{- "Políticas culturales y sociedad de la infor- mación"}

La sociedad de la información es una realidad sobre la que las instancias públicas no deben quedar al margen. Su objetivo es claro: democratizar el acceso a las nuevas tecnologías, a sus lenguajes y a su uso como herramienta de comunicación tanto a nivel personal como laboral.

\section{- "Cultura y política cultural"}

Una reflexión sobre el papel de la política, el papel de sus agentes, la gestión del talento desde ópticas de estado o de mercado y una apuesta por una geostrategia cultural. Representantes de todos los sectores implicados han aportado sus opiniones.

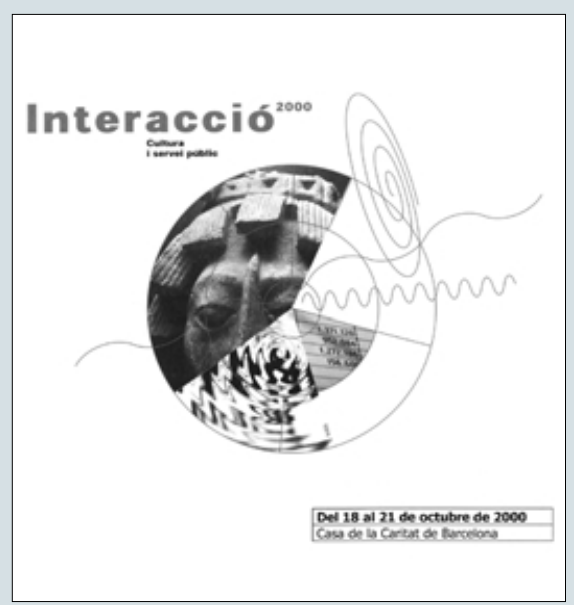

Pero Interacció 2000 no quiere limitarse a ser un conjunto más o menos harmónico de seminarios. Se ha ofrecido la posibilidad de tratar en vivo y en directo a directivos de equipamientos de primera fila de la ciudad. Así, en formato de una visita a las instalaciones que terminaba con una comida con algunos de sus máximos representantes, se han organizado grupos al Museo Nacional de Arte de Cataluña, el Gran Teatro del Liceo, El Foro Universal de las Culturas para el 2004, la nueva sede del Instituto del Teatro y el Teatro Nacional de Cataluña. Así, se ha dado respuesta a diferentes sectores de la cultura.

Y se ha ido más lejos todavía. Para aquello que requería más tiempo, se han organizado tres itinerarios de larga duración el sábado en la mañana con un título genérico: ¿Puede la cultura salvar la ciudad? Los temas propuestos han sido:

\section{- "Calles temáticas. Una aproximación al gremialismo postmoderno"}

El eje vertebrador ha sido la especializa- ción en el pequeño comercio cultural de tres sectores de la ciudad vieja

\section{- "La sombra del Sónar es alargada"}

Se ha querido ver como a partir de un festival de músicas avanzadas se ha ido constituyendo en diferentes partes de la ciudad circuitos y servicios comerciales ligados al contenido y a la estética propia del Sónar.

\section{- "Equipamientos, monumentos, instrumen- tos..." \\ Una propuesta por tres centros culturales polivalentes que han destacado por su mo- delo de gestión, su programación o su re- lación con su territorio.}

Paralelamente se han llevado a cabo cuatro foros en los que han debatido, en sendas reuniones, los representantes invitados de administraciones locales de Cataluña, España, Europa y América Latina. Los resultados son esperanzadores por lo que respeta a la creación de iniciativas conjuntas, redes de intercambio y avances en la definición común de la responsabilidad del sector público en la vida cultural local.

Interacció quiso concluir su programa de contenidos con un encuentro informal de gestores culturales de todo el Estado español para, después de debatir durante tres días sobre la temática que nos ocupa, abordar la necesidad de reflexionar sobre la situación actual y las perspectivas que se presentan en la siempre difícil pero necesaria consolidación profesional de los gestores culturales.

Interacció 2000 ha terminado y cada cual vuelve a su puesto de trabajo con más ideas y nuevas dudas constructivas en la cabeza, con las ganas de implementarlas y de mejorar su proyecto al llegar, con un conjunto de documentos bajo el brazo, con algunas horas pasadas aprovechando el oportuno centro de documentación del CERC y con nuevos contactos en la agenda de personas que, aquí o allá, están inmersas en proyectos y realidades más parecidos a los nuestros de lo que a veces queremos creer. Ha valido la pena este pequeño esfuerzo para este enorme resultado.

¡Hasta el próximo Interacció!

David Roselló y Cerezuela Coordinador técnico Interacció 2000 